\title{
Effects Of Using Gagne's Learning Hierarchy On Chemistry Students' Academic Achievement And Anxiety Level In Balancing Chemical Equations In Secondary Schools In Katsina Metropolis, Nigeria.
}

\author{
Sabiru Dahiru Yusuf \\ School Of Sciencefederal College Of Education, Katsina
}

\begin{abstract}
This study investigates the Effects of Using Gagne's Learning Hierarchy on Chemistry Students' Academic Achievement and Anxiety level in Balancing Chemical Equations in Secondary Schools. The study sample used 100 SSII students randomly selected from two Senior Secondary Schools in Katsina Metropolis. The two schools were randomly placed as experimental and control groups each with 50 students. A quasiexperimental pretest-posttest research design was used for the study. The study subjects in the experimental group were taught using Gagne's learning hierarchy, while the control group was taught using lecture method for the period of six weeks. Two instruments; Balancing Chemical Equation Achievement Test (BCEAT), and Students' Anxiety Scale Questionnaire (SASQ) with reliability coefficient of 0.79 and 0.78 respectively, were used to collect data for the study. Performances of the two groups were compared using their posttest mean scores. The major findings from the study are: Students taught using Gagne's learning hierarchy recorded high academic achievement than those taught using to lecture method. The anxiety level of students taught using Gagne's learning hierarchy tended to be low when compared with students taught using lecture method. Based on the findings, the following recommendations were made: Chemistry teachers should as much as possible arranges concepts taught in Chemistry hierarchically so that students can learn the simple concepts which will help their understanding of abstract or complex concepts.
\end{abstract}

\section{Introduction}

Chemistry is one of the important science subjects taught at the Senior Secondary School (SSS) level. It is one of the core science subjects that students are required to pass at credit level in order to qualify for admission into tertiary institutions to pursue science - based programmes. Examples of such courses are Food science and nutrition, Medical sciences, Pharmaceutical sciences, Agricultural sciences, and Earth sciences.

In spite of this central and important position of chemistry among other science and related disciplines, studies revealed that, academic achievement of students in chemistry at Senior Secondary School Certificate Examinations (SSSCE) has consistently been very poor and unimpressive ( Njoku, 2005). Many factors have been suggested as contributing to this poor performance of students in chemistry in particular and sciences in general. Some of these factors include: inadequate laboratory infrastructure and equipment in Chemistry ( Eniayeju, 2001); poor teaching methods, lack of adequate practical equipment, mathematical nature of chemistry concepts and laws (Ayogu, 2001); psychosocial factors (Bankole,2001); Also the West African Examination Council (WAEC) Chief Examiners Report 2004, 2005, 2006, 2007, and 2009, reported students' general poor performance in chemistry, as seen in Table 1.1

Table1.1 Performance of Students in Chemistry at SSCE Level (WAEC) from 2005 to 2010 in Nigeria

\begin{tabular}{cccccc}
\hline YEAR & $\begin{array}{c}\text { No OF } \\
\text { STUDENTS } \\
\text { PRESENT }\end{array}$ & $\begin{array}{c}\text { No OF } \\
\text { STUDENTS } \\
\text { PASS }\end{array}$ & $\begin{array}{c}\text { No OF } \\
\text { STUDENTS FAIL }\end{array}$ & \% PASS & \%FAIL \\
\hline 2005 & 182659 & 39125 & 143534 & 21 & 79 \\
2006 & 228953 & 80355 & 148598 & 35 & 65 \\
2007 & 250099 & 86150 & 163949 & 34 & 66 \\
2008 & 289520 & 84520 & 205000 & 29 & 71 \\
2009 & 326541 & 98215 & 228326 & 30 & 70 \\
2010 & 367562 & 120560 & 247002 & 33 & 67 \\
\hline
\end{tabular}

Source: WAEC Office Kaduna,(2011).

In Katsina State where this study was carried out, the situation is not very different as can be seen in Table 1.2, which shows the performance of chemistry students from 2005 to 2010 . The analysis showed that students have problem with chemistry subject at the SSSCE and poor passing grades fluctuate within the years under consideration 
Table 1.2 Performance of Students in Chemistry at SSCE Level (WAEC) in Katsina State, from 2005 to

\begin{tabular}{cccccc}
\multicolumn{2}{c}{ 2010. } \\
YEAR & $\begin{array}{c}\text { No OF } \\
\text { STUDENTS } \\
\text { PRESENT }\end{array}$ & $\begin{array}{c}\text { No OF } \\
\text { STUDENTS } \\
\text { PASS }\end{array}$ & $\begin{array}{c}\text { No OF } \\
\text { STUDENTS FAIL }\end{array}$ & \% PASS & \%FAIL \\
\hline 2005 & 1700 & 395 & 1305 & 23 & 77 \\
2006 & 1800 & 355 & 1445 & 20 & 80 \\
2007 & 1905 & 340 & 1565 & 18 & 82 \\
2008 & 2030 & 403 & 1627 & 20 & 80 \\
2009 & 2210 & 401 & 1809 & 18 & 82 \\
2010 & 2560 & 528 & 2032 & 21 & 79 \\
\hline
\end{tabular}

Source: Katsina State Ministry of Education(2011).

From Table 1.1 and 1.2, it could be seen that chemistry students have problems/difficulties in the learning of chemistry which has resulted in poor performance at Senior Secondary School level.

The concept of balancing chemical equations has been recognized as one of the basic chemical concepts in chemistry, as suggested by Ababio, (2004). Anthony (2009) reported that the understanding of balancing chemical equation is a prerequisite to the comprehension of some learning tasks in chemistry such as chemical equilibrium, electrochemistry and organic chemistry. Balancing chemical equations also is one of the difficult concepts chemistry students encounter in both practical and theory. This is supported by WAEC chief examiners' reports of 2007, 2008, and 2009, which ascertained that, what made most chemistry students perform poorly in chemistry, was the inability of the students to write correctly, reactants, products as well as to balance the reaction equation correctly. Therefore, there is a need to find away of solving this problem.

A number of activity-oriented instructional strategies have been advocated for by curriculum designers and science educators (Eniayeju, 2001) to help improve on the failure rate among secondary school science students. Examples of these strategies include guided discovery approach, demonstration method, discussion method and problem-solving for teaching senior secondary school chemistry as stipulated in National Policy on Education (FME, 2004). Research findings had however, revealed that to date, a large proportion of science teachers, chemistry inclusive, still resort to the use of traditional/lecture method rather than the activity-oriented strategies advocated for, such as demonstration method problem-solving and others (Olorukooba,2001).

For the concepts in chemistry to be taught effectively to chemistry students in the secondary schools, Gagne's theory of learning hierarchy of science teaching and learning has been considered relevant and fruitful (Kearsley 1999). Gagne' theory of learning hierarchy has advocated for the hierarchical structure where learners are exposed to different concepts from simple to complex concepts. In this study, therefore, the effects of using Gagne's learning hierarchy on balancing of chemical equation in chemistry, and to investigate its effect on students' academic achievement in balancing chemical equation and anxiety on SSS chemistry students.

Robert Gagne's theory of learning is often referred to as Gagne's theory of learning hierarchy (Kearsley, 1994). According to Gagne, the learning of a new concept or skill depends upon the mastery of pre- requisite concepts which are hierarchically arranged. This implies that prior knowledge determines what further learning may take place, which also implies that materials meant for learning must be sequentially structured by the teacher. The importance of Gagne's learning hierarchy in the teaching of chemistry is that, it will allow students to achieve meaningful learning through the movement from previous learnt material to abstract material. For instance before the Senior Secondary School students comprehend concept of balancing chemical equation (abstract material), they must be familiar with lower concepts/prerequisite, like concepts of atoms, molecules, compounds, ions, symbols, atomic number, simple chemical combination and so on (previous learnt material). And the arrangement of the simple learning task (prerequisite) to complex task (new knowledge), is what is called learning hierarchy according to Gagne's theory of learning.

It is based on this learning theory, (i.e. Intellectual skills development) which was organized in a hierarchy according to complexity by Gagne that this study was based. This learning hierarchy therefore served as a guide in teaching the topic of balancing chemical equation in chemistry, with the hope of enhancing academic performance of the students in the topic, as well as reducing the anxiety level of the students in the topic taught.

Studies such as Tobias, (1999) and Elliot, (2000) have shown that test anxiety affects performance of science students. Anxiety is defined as an unpleasant sensation that is usually experienced as feelings of apprehension and general irritability accompanied by restlessness, fatigue, and various somatic symptoms such as headaches and stomachaches (Chiss and Hassibi, 1998). Anxiety may affect the academic performance of students according to (Elliot,2000) this is called test anxiety. In other words, test anxiety is a reaction to examination stress, that is, the stress caused by testing conditions, such as examination. In this study therefore, the effect of using Gagne hierarchy of learning on anxiety level, will be investigated. 


\section{Statement of the Problem}

Science educators, parents and other stakeholders in science education had been worried about the poor performance of students in SSCE and WASCE chemistry for quite some time now. In spite of the important position of chemistry among other science subject and related disciplines, literature have revealed that, students performance in chemistry at Senior Secondary School Certificate Examination (SSSCE) have been poor consistently, ( Njoku 2005 and WAEC Chief Examiners' report 2005- 2010).

A study carried out by Anthony (2009) revealed that SSS students have difficulties in learning certain chemical concepts such as solubility, electrolysis, redox reaction, chemical equilibrium and balancing chemical equations. To achieve mastering of balancing chemical equation and other concepts in chemistry, several instructional strategies are device over the years. The earliest and perhaps the least affective teaching method is the expository method, commonly referred to as the traditional method, the lecture method or the chalk and talk method. Over the years science educators have been using the lecture method of teaching balancing chemical equations with little or no activities, which makes the concept difficult for students to grasp (Anthony 2009).Also studies by Tobias, (1999) have shown that test anxiety affect the performance of students in examination.

It is in line with this problems (that is poor academic achievement, difficulties in learning certain chemical concepts such as solubility, electrolysis, balancing chemical equation among others, application of teacher centered method in handling difficult concepts, high students' anxiety level), the study sought to investigate the effect of using Gagne's learning hierarchy on students' academic achievement and anxiety in balancing chemical equation at SSS level to see what the result will be.

\section{Objectives of the Study;}

The objectives of the study are to;

- Determine the effect of using Gagne's learning hierarchy on chemistry students' academic achievement in balancing chemical equations at SSS level.

- determine the effect of using Gagne's learning hierarchy on anxiety level of students in balancing chemical equations at Senior Secondary School level;

\section{Research Questions}

The study sought answer to the following questions.

(1) Is there any difference in academic achievement of Senior Secondary School Chemistry Students when exposed to Gagne's learning hierarchy and those exposed to lecture method in balancing chemical equations?

(2) What is the difference in anxiety level of Senior Secondary School Chemistry Students when exposed to Gagne's learning hierarchy and those exposed to lecture method in balancing chemical equations?

\section{Hypotheses}

The study had the following null hypotheses to be tested at $\mathrm{p}<=0.05$

$\mathbf{H o}_{1}$ : There is no significant difference in academic achievement of SSS chemistry students exposed to Gagne's learning hierarchy in balancing chemical equation and those exposed to lecture method of teaching.

$\mathbf{H o}_{2}$ : There is no significant difference in the anxiety level of senior secondary school chemistry students exposed to Gagne's learning hierarchy and those exposed to lecture method of teaching.

\section{Significance of the Study}

The findings of this study will certainly uplift the standard of chemistry education in the following ways.

1. Through enhancing the academic achievement of chemistry students.

2. Through minimizing/reducing chemistry student's anxiety level.

\section{Methodology}

In this study quasi- experimental- control groups design, involving pre and posttests was used. The study involved control and experimental groups consisting of both male and female study subjects. A pretest was administered to the groups, before the treatment, to determine the group comparability of experimental and control groups' ability level. The experimental group was taught the concept of balancing chemical equations using Gagne's learning hierarchy. The control group was taught the same concept using the lecture method. At the end of the treatment period, a posttest was administered to both groups of students in order to determine the effectiveness of the treatment on balancing chemical equation. 


\section{Population of the study}

The population of this study comprised all the Public Senior Secondary II Chemistry students (SS II) in Katsina metropolis of Katsina state of Nigeria. The population comprises of single sex and co-educational schools; there are two (2) male schools, two (2) female schools and six (6) co-educational schools in the population. The age range of the students is between $15-18$ years old.

\section{Sample and sampling procedure}

Simple random sampling technique involving 'balloting method' was used to select two Senior Secondary Schools out of the ten Senior Secondary Schools in the population. This was done by written the name of each secondary school on pieces of paper, and a child was asked to pick two papers randomly. The selected schools were (1) Government Senior Secondary School Kofar Yandaka, (2) Government Senior Secondary School Kofar Kaura. Study subject where also selected using stratified random sampling.

\section{Instrumentation}

Two instruments were used for data collection they are: Balancing Chemical Equation Achievement Test (BCEAT), and Students' Anxiety Scale Questionnaire (SASQ). Both the instruments were validated by experts in chemistry and psychology. The reliability coefficient of BCEAT were found at $r=0.79$.

The questionnaire was divided into two sections; section A which comprises of students' personal data response while section B consist of a 5-point Likert scale responses (i.e. strongly agree, agree, undecided, disagree, strongly disagree) which is on students' anxiety level. The reliability of the instrument was estimated by split half method using Pearson product moment correlation coefficient (PPMCC) statistics and SpearmanBrown prophecy formula. This formula yields a reliability of 0.78 .

\section{Procedure for data collection}

For effective data collection the two groups (i.e experimental and control groups) were taught separately for six weeks. The instruments developed by the researcher were administered both at the beginning i.e pretest and after the treatment as posttest and students responded to the items in the presence of the researcher.

Students' anxiety scale questionnaire (SASQ) was also administered to both experimental and control group, before and after the treatment. After the students have completed their responses, the questionnaire was collected and subjected to the data analysis.

\section{Data analysis technique}

The data generated from the Balancing Chemical Equation Achievement Test (BCEAT) were analyze using t-test unrelated sample. The other data which was generated from the Students 'anxiety scale questionnaire (SASQ) was coded before applying t-test unrelated sample to analyze the data The significant level for rejection or acceptance of the hypotheses is $\mathrm{p}<\ldots 0.05$.

\section{Results Analysis and Discussion}

Hypothesis 1. There is no significant difference in the academic achievement of SSS chemistry students exposed to Gagne's learning hierarchy in balancing chemical equations and those exposed to lecture method. The results are presented in Table 1.3

Table 1.3 t-test Analysis of Difference in Achievement of the Experimental andControl Groups.

\begin{tabular}{llllllll}
\hline Groups & $\mathrm{N}$ & $\overline{\mathrm{X}}$ & $\mathrm{SD}$ & $\mathrm{df}$ & t-value cal. & P & Remark \\
\hline Experimental & 50 & 67.34 & 13.12 & & & 0.000 & Significant \\
Control & 50 & 52.84 & 10.86 & & & & \\
\hline
\end{tabular}

Significant at $\mathrm{P} \leq 0.05$

From Table 1.3, it is evident that the calculated t-value of 6.02 is greater than t- critical value of 1.67 at $\mathrm{df}(98)$. In addition, the calculated p-value of 0.000 is less than 0.05 level of significance. Therefore, the null hypothesis of no significant difference is rejected. This implies that students' exposure to Gagne's learning hierarchy has produced significant difference among the experimental and control groups. Thus there is statistically significant difference in the academic achievement SSS Chemistry Students exposed to Gagne's learning hierarchy in balancing chemical equation and those exposed to lecture method. The significant effect was in favor of the experimental group. The findings of the study affirmed the earlier findings of studies by Bajah and Bello (1999), 
Adetula (2000) and Oyoleye (2001) who noted that students taught using Gagne's learning hierarchy tend to record significantly high academic achievement when compared with those taught using lecture method.

Hypothesis 2. There is no significant difference in the anxiety level of SSS chemistry students exposed to Gagne's learning hierarchy and those exposed to lecture method. The SASQ result was coded to enable the researcher convert the data from Ordinal scale to Interval scale, (Awotunde and Ugodulunwa, 2002). Based on the result obtained after coding the result, the t-test was applied to find significant difference between Anxiety level of Chemistry students and their Academic achievement in balancing chemical equations.

Table 1.4 t-test Comparative Analysis of Students' Anxiety Level between Experimental and Control Groups in Balancing Chemical Equations.

\begin{tabular}{llllllll}
\hline Groups & $\mathrm{N}$ & $\mathrm{X}$ & $\mathrm{SD}$ & $\mathrm{df}$ & $\mathrm{t}$-value cal. & $\mathrm{P}$ & Remark \\
\hline Experimental & 50 & 47.50 & 15.13 & & & \multirow{2}{*}{ Significant } \\
Control & 50 & 62.00 & 15.82 & & & & \\
\hline
\end{tabular}

Significant at $\mathrm{P} \leq 0.05$

At df 98 the calculated $t$-value and p-value at alpha level of 0.05 are respectively 4.68 and 0.000 (Table 1.4). This means that there are significant difference on the anxiety level between those students in experimental group and those in control group. By extension, it implies that students taught using Gagne's learning hierarchy tend to have low anxiety than those taught with lecture method in balancing chemical equations. Therefore, the null hypothesis of no significant difference on students' anxiety level is rejected. This supports the assertion of Tobias (1999), Ellion, (2000) that the anxiety level of SSS students are affected (lowering) by the influence of induced activity based

\section{Conclusion}

From these findings, the following conclusions are drawn:

Gagne's learning hierarchy has helped in improving the academic achievement of senior secondary school chemistry students, as well as their anxiety level. Therefore Gagne's learning hierarchy is viable and has potential of enhancing senior secondary school chemistry students' academic achievement in balancing chemical equation.

\section{Recommendations}

Based on these findings, the following recommendations are made:

1. In terms of academic achievement, this study shows that Gagne's learning hierarchy enhanced the academic achievement of the subjects in chemistry as compared to lecture method. The use of Gagne's learning hierarchy by chemistry teachers should therefore be encouraged in Nigerian secondary schools.

2. A part from the use of Gagne's learning hierarchy in improving academic achievement, the findings of this study also showed that anxiety level of students in a Gagne's learning hierarchy class is lower than the anxiety level of the students taught using Lecture method. In education, it is hard to think of any goal for which lowering an anxiety level is not important. The implication of this is that the use of Gagne's learning hierarchy should be encouraged in the science classroom because of its efficiency in lowering the anxiety level of the students.

[1]. Ababio, O. Y. (2004). New School Chemistry for Senior Secondary Schools. Africana First Publisher's Limited Book House trust, 1 Africana first Avene Onitsha, Nigeria.

[2]. Adetula, L.O. (2000) Teaching to Improve Students'problem Solving Abilities. African Mathematic Series. 2 (1) 139-144

[3]. Anthony A.D. (2009).The Effect of Simulation Games on Senior Secondary School Students' Performance and Attitude towards Balancing of Chemical Equations. An MPHIL Dissertation presented to the Dept. of Science Education, Winneba Ghana.

[4]. Awotunde, P.O. and Ugodulunwa, C.A. (2002) An Introduction to Statistic Methods in Education. Fab Anien Nigeria.

[5]. Ayogu, Z. U. (2001). Enriching Science, Technical and Mathematics Education. 41th National Conference Proceedings of the Science Teachers Association of Nigeria. 396-398.

[6]. Bajah, S.T. and Bello, O.O. (1999). The Effects of Enhanced Problem-Solving Strategy on Chemistry Achievement. Journal of Science Teachers Association of Nigeria. 25 (2), 42-45.

[7]. Bankole, D. (2001, July, 21). State of Education in Nigeria The Guardian. 7-8

[8]. Chiss, L.I. and Hassibi, R. (1998). Anxiety in Academic Achievement Situation. Journal of Abnormal and Social Psychology._61, 207-215. Retrieved May 7, 2010 from http://funbasedlearning.com/edu/default,htm.

[9]. Elliot, H.G. (2000). Links and Nodes in Problem-Solving. Journal of Chemical Education 5, (9), $717-726$

[10]. Eniayeju, D. (2001).Competencies Required of Science Education Teachers. A Paper Presented at the $24^{\text {th }}$ Annual Conference of the Science Teachers Association of Nigeria.

[11]. Federal Republic of Nigeria, (2004). National Policy on Education: Lagos, $4^{\text {th }}$ edition, NERDC Press..

[12]. Katsina Zonal Education,(2010). Katsina State, Nigeria.

[13]. Kearsely, G.(1994). Condition of Learning (R.Gagne) (on line) Available. http://www-gwu-edu/-tip/gagne.htm/dec 1, 27/10/2011

[14]. Kearsely, G. (1999). Explorations in Learning and Instruction: the Theory into Practice (online).Available: http://www.gov.edu.futip. 27/10/2011 
[15]. Njoku, Z.C (2005). Level of Chemistry Practical Science Skills Acquired by Senior Secondary School (SS II) Students. Nigerian Journal of Professionals Teachers.

[16]. Olorukooba, S.B. (2001). The Relative Effects of Cooperative Instructional Strategy and Traditional Methods on the Performance of Senior Secondary School Chemistry Studies. An Unpublished Ph.D Dissertations A.B.U Zaria

[17]. Oyoleye, O. (2001). Relationship between Junior Secondary School Students Performance in Mathematics Problem-solving Test and Test of Intellectual Abilities Abacus. The Journal of Mathematics Association of Nigeria, MAN,26 (1) 56-69.

[18]. Tobias, S. (1999). Test Anxiety. Interference, Defective Skills, and Cognitive Capacity. Educational Psychologyist. 20, 135-142. Retrieved May 27, 2009 from http://funbasedlearning.com/psyc/default,htm.

[19]. West African Examination Council Zonal Office, (2010). Kaduna.

[20]. West African Examination Council (WAEC 2004, 2005, 2006, 2007and 2008). Chief Examiner's Report, Senior Certificate Examination. May/June 2006 101-112. 